\title{
“Não Havia Outra Escolha Possível": Conformismo, Conformidade E ConfirmaÇÃo - UMA ABORdAGEM \\ Psicanalítica Do DeVIR-Desistente \\ OU DO DEVIR-PERSISTENTE
}

Jean-Michel Vivès1

\section{Resumo}

A partir de uma diferenciação precisa do sentido dos termos de conformismo, conformidade e confirmação, o autor se propõe a descrever os mecanismos psíquicos em jogo no devir-desistente (o que implica em ceder de seu desejo) e no devirpersistente (que teria a ver com a perlaboração do desejo). Este percurso do conformismo à confirmação permite precisar o aforismo lacaniano em relação à ética da psicanálise: "Agistes em conformidade com teu desejo?".

Palavras-Chave: Conformismo, Conformidade, Confirmação, Desejo, Ética, Supereu, Voz.

1 Professor de Psicologia Clínica e Patológica pela Université Nice Sophia Antipolis (França).

Psicanalista à Toulon (França). E-mail: jeanmichelvives@gmail.com 
Texto originalmente apresentado como conferência no IX Encontro Nacional e IX Colóquio Internacional do Corpo Freudiano Escola de Psicanálise "O mundo e o imundo - a psicanálise diante do horror", realizado nos dias 14, 15 e 16 de novembro de 2019 no Hotel Vila Galé, Lapa, Rio de Janeiro (Brasil).

Tradução para o português do Brasil feita por Maysa Pucinelli. Revisão da tradução realizada por Renata Mattos Avril. As notas de tradução ao longo do texto foram escritas por ambas.

Minha intervenção encontra sua origem na surpresa, para não dizer sideração, que me tomou ao escutar uma colega psicanalista brasileira afirmar, ao tomar a palavra em público durante uma jornada em homenagem à Alain Didier-Weill organizada pela associação Insistance no New Morningde Paris em junho deste ano, que ela tinha votado em Jair Messias Bolsonaro, justificando seu voto com um argumento indiscutível: "Não havia outra escolha possível". Em sua tomada de posição nesta assembleia, não faltou coragem. Escutou-se um murmúrio entre os presentes, mas eles foram delicados o suficiente para não insistir. Meu propósito aqui não é julgar a escolha desta colega: por não viver no Brasil, me seria difícil avaliar o cotidiano de seus habitantes que foi capaz de conduzir um número suficiente de brasileiros a levar até a função presidencial um personagem que, visto da França, revela mais do palhaço do que do Messias.

Assim, como os pacientes acometidos por uma coulrofobia - ou seja, pela fobia de palhaços, e imagino que neste momento isto ocorra com uma grande maioria de vocês - puderam perceber, sem nunca terem visto o filme "It: a coisa" 2 : por trás da figura do palhaço, pode se revelar uma encarnação do supereu feroz e obscena. $O$ palhaço, que por ocasião pode ganhar o aspecto de uma personagem providencial, é então inconscientemente uma incarnação desta instância sem poder real, mas, ainda assim, terrível que é o supereu e que não cessa de nos propor a via da desistência.

Para esclarecer esta dimensão, eu me deterei à enigmática e abrupta justificativa trazida por esta colega: "Não havia outra escolha possível". Meu incômodo não vinha apenas de sua escolha política. Efetivamente, tendo muitos "amigos" brasileiros no Facebook, eu já havia constatado um número assustadoramente alto 
de psicanalistas brasileiros que poderiam sustentar ativamente esta candidatura, por assim dizer... atípica. Em um primeiro tempo, eu nutria a esperança de que se tratava apenas de alguns colegas desnorteados da IPA. Que meus confrades desta venerável instituição queiram me perdoar por este pensamento que revela mais de meus preconceitos do que da realidade... De fato, não era o caso, e logo percebi que colegas analistas se valendo do ensino de Lacan poderiam igualmente sustentar esta candidatura, ou ao menos alinharem-se a ela, pois "não havia outra escolha possível". Aí está um primeiro paradoxo apaixonante: seria então possível ler Lacan, sustentar com ele a existência de uma escolha ética no contexto de uma análise e, paralelamente, declarar fora da clínica que não há outra escolha possível.

O que conduz um psicanalista - que em sua trajetória descobre-se filha ou filho da palavra e cuja prática cotidiana sustenta-se pela suposição de que, justamente, uma escolha outra àquela do sintoma, da inibição ou da angústia é possível - a afirmar fora do consultório: "Não havia outra escolha possível"?

Eu me interessarei aqui por buscar determinar o que conduz um sujeito a escolher se engajar nisso que poderíamos nomear um devir-desistente ou um devirpersistente. Para tanto, proponho distinguir três noções que poderiam, à primeira vista, parecer próximas, mas que implicam, no entanto, em posições subjetivas bem diferentes e nas quais subjazem o trajeto da desistência até a persistência. Estas três noções são o conformismo, a conformidade e a confirmação.

A hipótese que submeto a vocês hoje é a seguinte: a impossibilidade de sustentar que uma outra escolha seja possível seria consequência de um movimento de desistência subjetiva, expressão da submissão à injunção: "Seja Conforme!", que surgiria assim que a confirmação da escolha em agir em conformidade com o seu desejo é impossível. Insisto mais uma vez, não se trata aqui de julgar o voto desta colega, mas de tentar compreender a posição subjetiva conformista que sustenta e que - escutem bem, isso é essencial para seguir aquilo que tentarei lhes dizer hoje nos concerne a todos. Há um admirador em potencial 3 à espera do Messias em cada um de nós e é importante o localizarmos para, justamente, não nos reduzir a isto. Recorrendo a uma formulação cara à Alain Didier-Weill, poderíamos dizer: "Eu não

3 Em sua obra Será que eu resistiria ao carrasco?, Pierre Bayard (2003, p. 21-27) interroga de modo bastante interessante a existência de uma personalidade potencial que poderia se revelar em condições extremas. 
sou apenas esta espera infantil de uma figura messiânica que viria me descarregar de ter que desejar e, assim, me confrontar com a castração". Entendam bem: a partir do duplo movimento de negação, trazido pelo "não" e pelo "apenas", o sujeito que sustenta esse enunciado reconhece que esta dimensão existe nele - aquilo que decai do simbólico, que nele ainda não adveio, ou que nunca será tratado por ele -, mas que é possível não se reduzir a ela, ainda que nem sempre seja fácil. Porque, como recorda Lacan, por ocasião do "Seminário 7", a escolha de uma ética heroica não é isenta de riscos e talvez, a partir disso, essa escolha eminentemente subjetiva e, portanto, solitária, não é possível para nem todos, nem em todos os momentos da nossa existência.

Assim, Lacan nos adverte:

O acesso ao desejo necessita ultrapassar não apenas todo temor, mas toda piedade (...). Sabe-se o que custa avançar numa certa direção, e meu Deus, se não se vai sabe-se por quê. Pode-se até mesmo pressentir que se não está totalmente esclarecido sobre suas contas com o desejo, é porque não se pôde fazer melhor, pois, não é uma via em que se possa avançar sem nada pagar (...) mesmo para aquele que avança ao extremo de seu desejo, nem tudo são flores (LACAN, 1959-1960/1997, p. 378).

Em seguida, ele acrescenta que, apesar disso, o sujeito em desistência não é enganado quanto "ao valor da prudência que se opõe (a esse engajamento na difícil via do desejo), quanto ao valor inteiramente relativo das razões benéficas, dos vínculos, dos interesses patológicos (...), que podem retê-lo nessa via arriscada (Ibid.)". Dito de outra forma, a via do desejo não é necessariamente prazerosa e podemos entender que é possível hesitar em nos engajar nela pois, como Lacan recorda, "é mais cômodo sujeita-se ao interdito do que incorrer na castração" (Ibid., p. 354). É esse movimento de desistência que leva a preferir o interdito à castração que eu proponho chamar de conformismo.

\section{O CONFORMISMO}

A etimologia da palavra conformismo remete-nos à ideia de idêntico: con- (cum, com) e forma. Estar em conformidade é submeter-se e entrar em uma forma imposta do exterior. Uma das ilustrações mais marcantes do conformismo é a célebre série de experimentos em psicologia social realizada entre 1928 e 1950 por Stanley Milgram, professor de psicologia na Universidade de Nova York. Seu objetivo era mostrar as 
condições de submissão a uma autoridade. Sob o pretexto de conduzir uma pesquisa sobre memória, Stanley Milgram pede que as pessoas inflijam choques elétricos crescentes em um sujeito supostamente testado, mas que, na verdade, é um comparsa-ator. Este, considerado objeto do experimento, é amarrado em uma cadeira, com um eletrodo preso ao braço. Ele deve restituir listas de pares de palavras aprendidas. Cada erro, previsto no dispositivo experimental, é sancionado por uma descarga elétrica de intensidade crescente. Os falsos choques elétricos seriam praticados por meio de uma máquina com trinta alavancas alternando de quinze a quatrocentos e cinquenta volts, com referências que variavam de "choque leve" a "atenção: choque perigoso"; os comparsas-atores simulavam medo e dor provenientes de descargas elétricas fictícias.

Sob o disfarce de testar métodos de memorização, a experiência provava, de fato, submissão a um protocolo que colocava em cena sessões de tortura. No entanto, a grande maioria das pessoas concordou em conduzir o experimento até o final, ou seja, infligir choques potencialmente mortais. Esses resultados perturbadores levaram Stanley Milgram (1974/2017, p. 38) a concluir que "pessoas ordinárias, desprovidas de qualquer hostilidade, podem, simplesmente ao executar sua tarefa, tornar-se agentes de um atroz processo de destruição". Em seguida, ele acrescenta:

\begin{abstract}
o que se revela surpreendente é constatar até onde a submissão de um indivíduo comum pode ir diante das injunções do experimentador. De fato, os resultados do experimento são ao mesmo tempo inesperados e perturbadores. Mesmo se levarmos em conta que muitos sujeitos sentem um estresse considerável e que alguns protestam contra o experimentador, a verdade é que uma proporção significativa deles continua até o nível de choque mais alto do estimulador (MILGRAM, 1974 [2017] p. 38).
\end{abstract}

Aqui, não podemos deixar de pensar nisso que Hanna Arendt (1963/2002) pôde qualificar de "banalidade do mal" em sua obra Eichmann em Jerusalém.

O que é notável aqui é o fato de que o conformismo implica, em um público que a priori não pretendia ocupar o lugar de carrasco, no abandono de toda a liberdade de pensamento para se colocar sob a vontade de um outro com o qual, no entanto, podese estar profundamente em desacordo. Esse segundo paradoxo é digno de interesse: o conformista não está necessariamente de acordo com o enunciado que ele profere. Ele se revela então um porta-voz no sentido mais forte da palavra. Ainda que a palavra que ele sustente possa estar em desacordo com seus princípios morais ou éticos, ele 
a suporta em todos os sentidos do termo, pois lhe parece que uma outra via/vozu não é possível.

Isso, infelizmente, não poderia surpreender os psicanalistas e já em uma carta de 4 de janeiro de 1928 dirigida a Ferenczi, Freud lamentou essa tentação do conformismo que ele mesmo podia identificar até mesmo entre seus alunos.

\begin{abstract}
As recomendações sobre a técnica que escrevi há muito tempo têm basicamente um efeito negativo. Eu considerei que era necessário, acima de tudo, enfatizar o que não se deve fazer e destacar as tentações capazes de prejudicar a análise. (...) $\bigcirc$ resultado foi que os analistas dóceis não compreenderam a elasticidade das regras que eu havia formulado e que elas as obedeciam como se fossem tabus (FREUD, citado por JONES, 1955/2006, p. 256. Grifo meu).
\end{abstract}

Poucos meses depois, em uma carta de 25 de novembro de 1928, ao seu amigo, o pastor Pfister, Freud (1909-1939/1966, p. 183) afirma veementemente querer proteger a psicanálise contra médicos e contra os padres, desejando com isso preservá-la de dois tipos de conformismo que poderiam atrapalhar o processo analítico: o furor sanandi médico por um lado, e a moralização religiosa normatizante, por outro.

O que Freud descobre com estupefação e um pouco de amargura é que a experiência da análise não necessariamente preserva o sujeito da deriva conformista. Isto nada tem de tranquilizador, mas devemos olhar para o fenômeno sem nos desviar para tentarmos compreender o que ele revela sobre a condição humana e sobre um dos limites da psicanálise.

Para darmos mais um passo adiante, vamos nos interessar por esta figura mítica do conformismo que é Ismênia, a irmã de Antígona, que, por ocasião da primeira cena da peça de Sófocles, responde as seguintes palavras a sua irmã que Ihe pede para ajudá-la a enterrar o irmão Polinices, para quem Creonte recusa uma sepultura.

ISMÊNIA: "E, hoje ainda, quando permanecemos nós duas sozinhas, imagine a morte miserável dentre todas que iremos padecer, tão rebeldes à lei, se desprezarmos o decreto, o poder absoluto de um rei. Perceba, antes, que nós somos apenas mulheres: a natureza não nos fez para lutarmos contra os homens; em seguida, que nós somos submissas a mestres, e desde então contrariadas a observar as ordens destes - e isso e ainda coisas mais duras... 
Por mim, em todo caso, eu suplico aos mortos sob a terra de me serem indulgentes, posto que, de fato, eu cedo à força; mas eu pretendo5 obedecer ao poder estabelecido (SÓFOCLES, 1973, p. 95. Grifos meus)".

Os argumentos apresentados por Ismênia para tentar convencer sua irmã Antígona a não enterrar seu irmão poderiam facilmente ser resumidos a um: "precisamos renunciar. Para continuarmos vivos; não há outra escolha possível". O interesse do posicionamento de Ismênia é ele que coloca em evidência aquilo que Christopher Browning propôs qualificar como conformismo de grupo a partir da análise que ele realiza sobre o comportamento de um batalhão da polícia alemã ao qual, em 11 de julho de 1942, fora solicitado assassinar mulheres, crianças e idosos, após uma captura maciça na Polônia de 1800 judeus. Este conformismo de grupo teria, de acordo com Browning, um papel importante na transformação desses "Homens Ordinários" - este é o nome de seu livro - em assassinos. Eu o cito: "Romper as fileiras6, dar um passo à frente, adotar um comportamento não conformista, estava simplesmente além de suas forças. Eles acharam mais fácil atirar" (BROWNING, 1992/2007, p. 270). Para eles também, parece que "não havia outra escolha possível". Neste caso, como no de Ismênia, poderíamos qualificar esse conformismo como conformismo de vida (VINOT, VIVÈS, 2016), o que implica que face à castração radical representada pela morte, o eu faz a escolha do narcisismo para se manter vivo.

O que leva o homem a se submeter a esse "havia7" impessoal que nos isenta de precisar escolher? Esta submissão, para além do tirano político, é uma submissão a um outro tirano bem mais pernicioso, posto que esta instancia intrapsíquica que todos nós partilhamos pode se revelar, de vez em quando, um aliado muito eficaz do tirano político. Vocês terão reconhecido aqui a figura do supereu em suas dimensões "obscena e feroz" destacadas por Melanie Klein e desenvolvidas por Lacan (1955/1966, p. 434). "Não havia outra escolha possível" é a expressão de uma desistência que revela como um sujeito, tenha sido ele analisado ou até mesmo sendo

\footnotetext{
5 Nota de tradução: No original, "mais j'entends obéir au pouvoir établi", o termo "entendre" utilizado na conjugação do presente na primeira pessoa do singular evoca tanto à dimensão de "pretender", no sentido de querer alguma coisa e de ter a intenção de fazer algo, como também a capacidade de escutar, a dimensão da escuta e, podemos também dizer, por consequência, da voz.

6 Sabemos que Antígona, face à Ismênia e ao coro que lhe pedem de conformar-se, escolhe "romper as fileiras".

7 Nota de tradução: No original, "IL", referente ao sujeito dos verbos impessoais como utilizados na língua francesa e que pode ser destacado na frase que estabelece o fio condutor deste escrito, a saber, "Il n'y avait pas d'autre choix possible", traduzido aqui como "não havia outra escolha possível". O verbo haver, no sentido de existir, pode ter a mesma função de indicar um sujeito impessoal, um verbo em que não há um sujeito definido.
}

Psicanálise \& Barroco em revista | v.17, n. 3 | dezembro de 2019 
um analista, pode se dispensar da responsabilidade não apenas diante dos deveres inerentes ao exercício da palavra, mas ainda igualmente diante daquilo que sua análise permitiu-Ihe experimentar:

- Primeiramente, que há apenas mundo se vencido o imundo. Este imundo deve ser entendido aqui em seu sentido etimológico que, embora não comprovado, é esclarecedor: um mundo negativado pelo prefixo -i. O i-mundo seria aquilo que ainda não atingiu a dimensão do mundo habitável. O imundo poderia ser escutado como um dos nomes do real.

- Em segundo lugar, que a lei simbólica pela qual o imundo pode se tornar um mundo não tem nada a ver com a lei superegóica, que seria antes o seu negativo. Porque, como lembra Lacan, a lei superegóica pode se revelar uma caricatura grotesca, clownesca, da lei simbólica:

um enunciado discordante, ignorado na lei, um enunciado promovido ao primeiro plano por um evento traumático, que reduz a lei a uma ponta cujo caráter é inadmissível, não integrável - eis o que é essa instância cega, repetitiva, que definimos habitualmente pelo termo supereu (LACAN, 19531954/1975, p. 222).

Como vocês já devem ter compreendido, o conformismo é o resultado da submissão e do impossível tratamento das injunções contraditórias do supereu: "Goze!" e "Não goze! ". A partir daí o conformista é culpado. Na verdade, ele não fica sem saber que ele cedeu ao seu desejo. Talvez seja por isso que ele faz tudo para reduzir ao silêncio aquele que se revele não conforme. O supereu, seja qual for a forma social - discursos fascistas de hoje, nazistas ontem, inquisidores anteontem tem o mesmo objetivo: silenciar qualquer voz dissonante. O objetivo sendo então o de fazer ouvir uma só voz para unificar a população. O processo, sabemos, é eficaz, como demonstrou Hitler promovendo a ideia

de um povo alemão como um mesmo corpo cuja saúde e pureza deveriam ser preservadas (...) o que permitiu unificar uma população que antes não 0 era, uma população que fora bastante marcada por "diferenças confessionais, pela sobrevivência de um forte senso de pertencimento à Terra e à província, ... pela feroz defesa obstinada de privilégios sociais e a afirmação de diferenças sutis nos hábitos respectivos" (LONGERIC, 2006; DE MIJOLA, 2016).

Esse fantasma de fazer Um a partir de elementos díspares foi descrito por Didier Anzieu (1981) sob o nome de ilusão grupal. Um objeto designado como ruim é 
então indicado como heterogêneo ao grupo e deve ser expulso para que tudo o que é bom, ou seja, homogêneo ao grupo, seja mantido em seu interior: sendo tudo aquilo que é heterogêneo rejeitado para fora. O grupo é assim protegido de tudo o que poderia contaminá-lo: a heterodoxia do herege para o inquisidor ou o judaísmo no caso do o nazismo. Encontramos aqui a dinâmica descrita por Freud (1915/2005, p. 182-183) em 1915 em "Pulsões e o destino das pulsões" a partir da dinâmica entre o eu-real inicial e o eu-prazer purificado, ao qual ele retornará dez anos depois em seu texto sobre a denegação (Freud, 1925/1982). Tomado por esta dinâmica da ilusão grupal, o grupo então se torna rebanho. Rebanho que logo responde à "voz de seu mestre" balindo com uma só vozв. Isso nos permite entender que "quando (a voz do) objeto de veneração desaparece, o pânico se instaura e pensamos, por exemplo, na sideração de muitos alemães em luto por seu ideal depois da morte de Hitler" (De Mijolla, 2016, p. 10). No mesmo movimento, Michelet (citado por Didier-Weill, 1995, p. 106), em sua "História da Revolução Francesa", revela o estranho silêncio que ocorreu em Paris quando o povo soube da fuga de Luís XVI a Varennes. Em ambos casos, a multidão permanece sem voz diante do desaparecimento daquele que lhe permitiu estruturar-se. O conformista - ainda que revolucionário - é falado pelo Outro e quando este se ausenta, revelando que não existe Outro do Outro, ele mergulha num silêncio onde o imundo - a ser escutado aqui mais uma vez como aquilo que não pôde advir ao simbólico - se faz escutar. Pois se

\begin{abstract}
o simbólico detém o poder de simbolizar o caos original que o recém-nascido encontra; neste encontro, onde o imundo se tornará mundo humano, a passagem de um para o outro não se faz harmoniosamente: a metáfora original não simboliza todo o real: um resto permanece em sofrimento, e é a este resto em sofrimento que o sujeito terá que lidar em seu destino (DIDIERWEILL, 2016, p. 10).
\end{abstract}

É desse resto, não tratado por ser intratável, que uma das faces do supereu tirará sua dimensão forclusiva. 


\section{CONFORMIDADE}

Convém mostrar agora como a conformidade se difere do conformismo, e podemos identificá-la precisamente se voltarmos à proposição de Lacan: "Agiste em conformidade com teu desejo? (Lacan, 1959-60, op. cit., p. 359)". Esta formulação permite escutar um significado que se abre na questão do acordo. "Agiste de acordo com o teu desejo?", poderíamos reformular. O que implica agir de acordo com o próprio desejo e não estar de acordo com o desejo do Outro? Lacan nos dá quanto a isso uma ilustração trágica a partir da sua leitura da Antígona de Sófocles na última parte de seu seminário 7. Isso já é bem conhecido e já foi amplamente comentado. Não me deterei nesse ponto. Para avançar, proponho outro caminho que nos permitirá esclarecer o que pode igualmente implicar em conformidade. Proponho começarmos pelo o caso do personagem de Melville, Bartleby, e seu famoso I would prefer not to ("Eu preferiria não"), tão difícil de traduzir. De fato, como podemos traduzir numa linguagem diferente da de Bartleby aquela fórmula que Jean Laplanche propõe qualificar como afirmação negativa?

\footnotetext{
Bartleby não diz não, ele não diz que não quer, ele não hesita tampouco entre um sim e um não, o seu "eu preferiria" não implica em nenhuma alternativa (preferiria isso àquilo). No I would prefer há de fato a afirmação, mas imediatamente contígua à negação do not para terminar - ou não terminar no suspense do not to. Não o quê? (PONTALIS, 2000, p. 13)9.
}

Bartleby está em conformidade, poderíamos dizer, com seu não-desejo. Ele manifesta um absoluto "desejo de não-desejo", para retomarmos a proposição pertinente de Piera Aulagnier (1975), que assim define a pulsão de morte. Um movimento que visaria o momento em que o desejo ainda não tivesse que ser atualizado. Trata-se aqui de um

não que se enuncia com uma voz átona, com uma insistência incrível, uma
firmeza implacável, mas sempre calma, um não que teria a doçura de um sim
consentindo, uma recusa em ceder a qualquer demanda, seja ela autoritária,
razoável, compreensiva, atenciosa ou até muito afetuosa. Bartleby é
intratável (PONTALIS, op. cit., p. 12. Grifo meu).

Esse adjetivo "intratável" é extremamente interessante, pois também qualifica Antígona no verso 472 da tragédia de Sófocles (op. cit., p. 109) : "A filha intratável de

9 Nota de tradução: os termos em inglês estão apresentados neste idioma no texto original em francês de Jean Pontalis. 
um pai intratável". Agir em conformidade com o desejo abre aqui duas vias que têm em comum expressar-se de modo intratável. Intratável, que não podemos fazer mudar de opinião, que se recusa a ceder. Os intratáveis: aqueles que não cedem do seu desejo, assim como aqueles que não cedem do seu não-desejo. A dimensão que aparece aqui é que a insistência pode às vezes ser reduzida ao que sua etimologia pode nos permitir identificar: in- no interior -sistere parar. A insistência pode então se transformar em uma pausa, uma parada perto da morte, na qual o sujeito tentaria manter-se à distância do desejo e de suas turbulências. É aqui que a conformidade em sua forma insistente pode revelar-se insuficiente, pois ela pode ocasionalmente se revelar insistência da pulsão de morte. É então necessário introduzir um mais-além da insistência, que seria persistência, e que proponho nomear como confirmação.

\section{CONFIRMAÇÃo}

A confirmação é uma consolidação e, nesse sentido, é a expressão de um simdo-sim. Um sim que é confirmado por uma repetição10. Ela é persistência no sentido em que sua etimologia nos permite ler nela uma travessia da parada (-per [através] / -sistere [parada]). Esta persistência pode ser aproximada do conceito freudiano, infelizmente pouco investigado pelos psicanalistas 11, de perlaboração. Esta aproximação entre persistência e perlaboração pode ser iluminada a partir do que Lacan pôde dizer sobre a análise didática, articulando-a à perlaboração. Uma psicanálise didática seria

uma psicanálise que tenha fechado esse cerco (cerco do processo analítico) até seu termo. O cerco deve ser percorrido várias vezes. Não há com efeito nenhuma maneira de dar conta do termo durcharbeiten, da necessidade de elaboração, se não é para conceber como o cerco deve ser percorrido mais de uma vez (LACAN, 1964/1996, p. 258).

A confirmação é a experiência da persistência que encontra expressão na dinâmica subjetiva que Lacan qualificou como autorizar-se (s'autoriser) e que Alain Didier-Weill modificou por se autor-izar (s'auteuriser)12. Neste sentido, se autor-izar

10 Este é o significado do sacramento da confirmação para os católicos.

11 Isso é ainda mais surpreendente, pois Freud (1914/2005) faz da perlaboração aquilo que distingue o tratamento analítico de todas as outras práticas psicoterapêuticas.

12 Nota de tradução: Em português esta nuance não é tão marcante, mas em francês a palavra-valise inventada por Didier-Weill insiste na dimensão da criação e da assinatura. Dito de outra forma, de se Psicanálise \& Barroco em revista | v.17, n. 3 | dezembro de 2019 
indica o momento em que o falante escolhe se tornar autor da palavra que ele recebeu do Outro. O sim-do-sim está ligado à persistência do desejo apesar da censura superegóica, do conformismo do grupo e/ou do medo do tirano quando o sim do conformista se revela aquiescente à submissão e à desistência.

O devir-persistente, aquilo que podemos esperar concernir ao analista, implica esta assunção do sim-do-sim da persistência, mas nada garante a passagem da insistência para a persistência e, deste modo, sua confirmação. Como o sujeito pode assumir e validar essa posição apesar de sua constituição sob um fundo de imundo? Como ele pode dizer "sim" a um mundo que permanece topologicamente relacionado ao imundo? Esse "sim" que pode ocorrer em uma psicanálise é, como Alain DidierWeill mostrou, um "sim" cuja complexidade está na articulação antinômica que ele deve produzir: o sujeito deve dizer sim ao que há de mais real nele, que não adveio ao simbólico ("Eu sou apenas isso", o que concerne o imundo) e dizer sim ao que, nele, contradiz o real ( "Eu não sou apenas isso"), advindo ao simbólico. Este "simdo-sim", pelo qual o sujeito assume, em um mesmo movimento, ser "isso" e "não apenas isso", é o ato pelo qual ele assumirá sua divisão de ser falante, o que permitirá que o "autorizar-se de" não seja um "autorizar-se por". "O analista tem horror do seu ato", nos adverte Lacan (26/01/1980).

O que há de tão horrível nesse ato que consiste em se autorizar a um ponto que alguns analistas gostariam de evitá-lo, convertendo-o em ato de obediência a uma escola, a um mestre ou mesmo a um Messias? Nada mais do que a castração simbólica, este ponto a partir do qual o real fura o simbólico e de onde ex-siste o desejo do analista, bem como o do analisando, de modo que o ato de se autorizar articula-se assim: "como saber se sou fiel a mim mesmo, ao que adveio em minha análise, quando digo que me tornei analista?" (Didier-Weill, 1991, p. 79). Aquele que recua diante do ato, no sentido analítico do termo, prefere a obediência a uma regra que lhe diz o que fazer, com o risco de se ritualizar, em vez da lei que o leva a dever improvisar13. De fato, como Lacan (1982/2001, p. 308) recorda, na nota italiana, "autorizar-se não é auto-ri(tuali)zar", caso em que a autorização seria apenas outro

tornar autor no mesmo ato de se autorizar. Poderíamos mesmo dizer que se autor-izar é o ato de se autorizar e de se tornar autor de sua própria palavra.

13 Sobre este tema, ver Lippi S., Vinot F., Cliniques Méditerranéennes $n^{\circ} 93:$ Improviser en psychanalys(t)e. Toulouse, Eres. 1996. 
nome para o conformismo, o que Freud já havia identificado, como lembramos anteriormente.

Então, o que seria a confirmação e o devir-persistente neste contexto? Para responder rapidamente a esta pergunta e concluir, retomo o célebre aforismo freudiano e proponho: "Lá onde estava, devo me confirmar me autor-izando". A autorização (auteurisation) sendo então entendida como o devir-persistente, outro nome da perlaboração, como proponho aqui, no lugar mesmo no inconsciente onde a confirmação se revela confirmação da palavra recebida e acolhida. Afinal, o sujeito só poderia ser um "homem de palavra". No sentido em que o sujeito se atém a ela, por ela, e assume as consequências que fazem com que diante da sempre presente tentação da escolha pelo imundo, a escolha da fidelidade à palavra, num incessante relançar, nos lembra que um mundo habitável e compartilhável é possível. Pois, como nos recorda Marc-Alain Ouaknin (1994, p. 68) de forma provocativa e quase herética, "O Messias é feito para não vir", oferecendo-nos em sua não-chegada o vazio da espera criativa no qual o sujeito é condenado a se autor-izar ou desaparecer 


\section{REFERÊNCIAS:}

ANZIEU D., Le groupe et l'inconscient. Paris, Dunod, 1981.

ARENDT H., (1963) Eichmann à Jérusalem. Paris, Gallimard/Folio. 2002.

AULAGNIER P., La violence de l'interprétation. Paris, P.U.F, 1975.

BAYARD P. Aurais-je été résistant au bourreau ? Paris, Editions de minuit, 2003.

BROWNING C., (1992) Des hommes ordinaires. Paris, Tallandier /Texto, 2007.

DE MIJOLLA S. «Le Conformisme en politique, dans l'éducation et en psychanalyse ». Topique, Conformisme et conservatisme, 2016, p. 7-20.

DIDIER-WEILL A., “Bénir, Maudire ou mi-dire Lacan ?”, Esquisses psychanalytiques. n¹5, 1991, p. 77-86.

DIDIER-WEILL A., Les trois temps de la loi. Paris, Seuil, 1995.

DIDIER-WEILL A., Qu'est-ce que le surmoi. Toulouse, Eres, 2016.

FREUD S., (1909-1939) Correspondance avec le pasteur Pfister, lettre du 25/11/1928. Paris, Gallimard, 1966.

FREUD S., (1914) « Remémoration, répétition et perlaboration », Euvres complètes, Tome 12, Paris, P.U.F. 2005, p. 185-196.

FREUD S., (1915) «Pulsions et destins des pulsions » dans Métapsychologie. Trad. Fr. Euvres Complètes, Tome XIII, Paris, P.U.F, 2005, p. 163-187.

FREUD S., (1925) La dénégation. Traduction et commentaires Theves P. et This B. Toulouse, Le Coq-Héron, 1982.

JONES E., (1955) La vie et l'œuvre de Sigmund Freud, tome 2 : Les années de maturité. Paris, PUF, 2006.

LACAN J., (1953-1954) Le Séminaire, Livre 1, Les écrits techniques de Freud. Paris, Seuil, 1975.

LACAN J., (1955) «La chose freudienne ou Sens du retour à Freud en psychanalyse », Écrits. Paris, Seuil, 1966.

LACAN J., (1959-1960) O seminário, livro 7, A ética da psicanálise. Rio de Janeiro, Jorge Zahar Editor, 1997.

LACAN J., (1964) O Seminário, Livro 11, Os quatro conceitos fundamentais da psicanálise. Rio de Janeiro, Jorge Zahar Editor, 1996. 
LACAN J., Dissolution, Journal le Monde, 26 janvier 1980.

LACAN J., (1982) « Note italienne », Autres écrits. Paris, Seuil, 2001.

LIPPI S., Vinot F., Cliniques Méditerranéennes $\mathrm{n}^{\circ} 93$ : Improviser en psychanalys(t)e. Toulouse, Eres. 1996.

LONGERICH P. (2006) Nous ne savions pas. Paris, Éd. Héloïse d'Ormesson, 2006.

MILGRAM S., Soumission à l'autorité. Paris, Fayard/Pluriel, 2017.

OUAKNIN M.-A. Bibliothérapie. Lire c'est guérir. Paris, Seuil, 1994.

PONTALIS J-B, «L'affirmation négative », Libres cahiers pour la psychanalyse, vol. 2, no. 2 , 2002.

SOPHOCLE, Antigone. Trad. Fr. Paul Mazon. Paris, Gallimard, 1973.

VINOT F., Vives J.-M., (2016) «Conformisme de vie, conformisme de mort », Topiques, Conformisme et conservatisme, $\mathrm{n}^{\circ} 136$. p. 91-101. 


\title{
“It Didn't Have Other Possible Choice”: Conformism, CONFORMITY AND CONFIRMATION - A PSYCHOANALYTICAL Approach Of The Becoming-Desistent Or Of The Becoming- Persistent
}

\begin{abstract}
Starting from a precise differentiation of the meaning of the terms of conformism, conformity and confirmation, the author proposes to describe the psychic mechanisms present in the becoming-desistent (which implies desisting, giving up one's desire) and in the becoming-persistent (which is related to the perlaboration of the desire). This path from the conformism to the confirmation allow us to precise the Lacanien aphorism correlated to the ethic of the psychoanalysis: "Have you acted in conformity with your desire?".
\end{abstract}

KEY WORDS: conformism, conformity, confirmation, desire, ethic, voice. 


\section{« Il N'y Avait PAS D'AUtRe Choix Possible »: \\ Conformisme, Conformite Et CONFIRMATION - UNE APPROCHE \\ Psychanalytique Du DeVeniR-Desistant \\ Ou Du DeVeniR-Persistant.}

\section{RÉSUMÉ}

À partir d'une différenciation précise du sens des termes de conformisme, conformité et confirmation, l'auteur s'attache à décrire les mécanismes psychiques en jeu dans le devenir-désistant (ce qui implique de céder sur son désir) et dans le devenir-persistant (qui aurait à voir avec la perlaboration du désir). Ce parcours du conformisme à la confirmation, permet de préciser l'aphorisme lacanien concernant l'éthique de la psychanalyse : "As-tu agi en conformité avec ton désir ?"

MoTS-CLÉS : conformisme, conformité, confirmation, désir, éthique, surmoi, voix. 
Jean-Michel Vivès

RECEBIDO EM 26-09-2019

APROVADO EM 20-10-2019

C 2019 Psicanálise \& Barroco em revista

http://www.seer.unirio.br/index.php/psicanalise-barroco/index

revista@psicanaliseebarroco.pro.br

Programa de Pós-Graduação em Memória Social — UNIRIO

Memória, Subjetividade e Criação

www.memoriasocial.pro.br/proposta-area.php 